\title{
EFEKTIVITAS PROGRAM TELEVISI TERHADAP PERKEMBANGAN KOMUNIKASI ORANG TUA PADA ANAK
}

\author{
Andi Edwin Rewira', Muhammad Ridwan ${ }^{2}$ \\ Institut Pembina Rohani Islam Jakarta (IPRIJA) \\ Email: rewira@gmail.com ${ }^{1}$,ridcampus@yahoo.com ${ }^{2}$
}

\begin{abstract}
This Research is motivated by the lack of communication between childrn and parents which has an impact on the occurrence of obstacles to the moral development of the child. This phenomenon is the effect of the advancement of mass media and the lack of attention from parents to their children. In response to this, it is necessary to conduct a study to determine the inhibiting factors of parent-child communication. thus, a solution to the existing problem will be obtained. In order to achieve these objectives in this study used qualitative-descriptive research methods with literature studies. The results of this study obtained data and fact about the negative effects caused by the mass media on the communcation relationship between children and parents as a result of the lack of parental attention to children in accessing mass media.
\end{abstract}

Keywords : communication, mass media, obstacle, ethics, solution

Abstrak: Penelitian ini dilatarbelakangi oleh kurangnya komunikasi antara
anak dan orang tua yang berdampak pada terjadinya hambatan
pembinaan akhlak sang anak. Fenomena tersebut merupakan efek
dari kemajuan media massa dan kurangnya perhatian orang tua
terhadap anak. Menyikapi hal tersebut perlu kiranya dilakukan kajian
guna mengetahui faktor penghambat komunikasi orang tua terhadap
anak. Dengan demikian akan didapat sebuah solusi dari permasalaan
yang ada. Guna mencapai tujuan tersebut dalam penelitian ini
digunakan metode penelitian kualitatfi-deskriptif dengan studi
pustaka. Hasil dari penelitian ini diperoleh data dan fakta adanya
efek negatif yang ditimbulkan oleh media massa terhadap hubungan
komunikasi antara anak dan orang tua akibat dari longgarnya
perhatian orang tua terhadap anak dalam mengakses media massa.

Kata Kunci : komunikasi, Media Massa, hambatan, etika, solusi 


\section{PENDAHULUAN}

Setiap hari kita menyaksikan televisi baik melalui televisi langsung maupun via media sosial. Setiap jengkal dirumah-rumah pasti memiliki televisi. Bahkan tidak sedikit yang rumahnya memiliki minimal dua buah televisi. Televisi sudah menjadi kebutuhan primer bagi setiap orang. Belakangan ini, kita sering melihat, mendengar dan membaca diberbagai media massa, baik itu cetak maupun media sosial tentang kenakalan remaja yang seakan tak pernah usai. Ada yang terlibat tawuran, terlibat tindakan amoral seperti pemerkosaan dan pergaulan bebas, bahkan yang hampir setiap hari ada beritanya adalah remaja yang mengedarkan narkoba dan juga sebagai pecandu. Ada juga yang menjadi tersangka dalam tindak kriminal seperti pembunuhan dan penjambretan. Lalu, siapakah yang salah dalam hal ini? Apakah guru sebagai pendidik, pemerintah yang mengelola program televisi atau orang tua kandung yang salah dalam hal mendidik?.

Beberapa pakar dibidang komunikasi, pendidikan dan sosial kemasyarakatan menilai etika cara berkomunikasi dan sistem pendidikan kitalah yang kurang menaruh perhatian kepada pendidikan akhlak seperti santun dalam berkata, tata krama dan budi pekerti. Porsi pendidikan agama yang didalamnya tercakup pendidikan akhlak sangat minim dibanding dengan ilmu-ilmu lain yang diberikan kepada anak didik kita. ${ }^{1}$ Program kajian agama di televisi masih kurang mencukupi porsi kebutuhan untuk anak. Bahkan bisa berbanding jauh jika dibandingkan dengan program hiburan.

Disisi lain, anak didik kita disekolah diminta untuk menyelesaikan target kurikulum sekolah yang ditetapkan oleh pemerintah dengan singkat baik belajar secara offline (tatap muka) atau online (daring). Sementara hal-hal yang berkenaan dengan pembinaan mental, kepribadian dan berfikir mandiri terabaikan.

Sebuah keluarga akan mencapai ketentraman dan ketenangan apabila orangtuanya dapat menjalankan tugas, peranan dan kewajibannya dengan baik. Sebagaimana Hasan Basri mengatakan bahwa keluarga adalah wadah pertama dan utama bagi pertumbuhan anak. Jika suasana dalam keluarga itu baik dan menyenangkan, maka anak akan tumbuh dengan baik pula. Jika tidak, tentu akan terhambatlah pertumbuhan fisik dan perkembangan mental anak itu. Peranan orang tua terutama Orang tua dalam keluarga amat penting. Dialah yang mengatur, membuat rumah tangganya menjadi surga bagi anggota keluarga. Menjadi mitra mengajar yang saling menyayangi dengan suaminya. ${ }^{2}$

Menurut Prof. Dr. H. Malik Fajar., mantan rektor Muhammadiyah Malang (UMM), yang juga mantan menteri agama mengatakan bahwa pendidikan kita perlu dikonstruksi dengan muatan-muatan intelektual yang seimbang dengan muatan agama. Artinya pendidikan agama harus ditambah porsinya dari yang sudah-sudah. Bahkan jika bisa, dapat diseimbangkan dengan mata pelajaran lainnya. Jika dicermati generasi muda sekarang sangatlah memprihatinkan, terlebih akibat pengaruh media sosial yang sudah tidak terbendung lagi, ditambah

\footnotetext{
${ }^{1}$ Muazim Syair, Porsi Pendidikan Agama Perlu Ditambah, Sriwijaya Post, Jumat 12 Mei 2005 (website sriwijaya pos)

${ }^{2}$ Hasan Basri, Keluarga Sakinah (Terjemahan Pshikologi dan Agama), Yogyakarta: Pustakan Pelajar, 2001, cet.4, h.87
} 
budaya dari luar yang membuat mereka mengabaikan tata krama dan sopan santun terhadap sesama bahkan yang lebih tua.

Sering kita mendengar dan membaca berita tentang amoralisasi atau tindakan asusila, baik dari media elektronik maupun media cetak. Yang lebih memprihatinkan adalah pelaku amoralisasi tersebut adalah anak-anak. Sebut saja pencabulan yang dilakukan oleh anak dibawah umur, pencurian di minimarket, pergaulan bebas hingga pulang larut pada dini hingga subuh hari. Dengan hal pergaulan seperti ini dapat menyebabkan anak mengarah pada perilaku pecandu narkoba dan seks bebas. Hal inilah yang membuat para orang tua dan guru sangat prihatin.

Menurut sebagian besar berita, dampak negatif yang ditimbulkan oleh media massa yang antara lain adalah siaran televisi dan media sosial saat ini. Siaran televisi saat ini lebih berpengaruh dibanding media yang lain. Sebagai contoh, anak-anak yang memperkosa teman sepermaianannya dikarenakan sebelumnya menonton film porno. Dan yang lebih mudah saat ini adalah dengan mengakses media sosial. Walaupun sudah ada aplikasi untuk memfilter website tersebut. Inilah salah satu dampak yang tidak baik jika tidak di filter.

\section{METODE PENELITIAN}

Metode Pengumpulan Data. Library Research atau Penelitian kepustakaan dilakukan peneliti dengan cara mengumpulkan buku-buku, artikel dari internet dan informasi yang ada hubungannya dengan masalah yang peneliti kaji. Metode Analisa Data. Dalam hal ini peneliti menggunakan metode analisa data dengan cara menganalisa data-data yang peneliti dapat dari buku-buku, surat kabar, dan semua yang bersangkutan dengan masalah yang dibahas.

Penelitian ini bertujuan untuk mengetahui faktor penghambat komunikasi orangtua terhadap anak. Efek negatif dari media elektronik yang terdapat pada program tontonan media sosial. Mengetahui faktor penyebab penghambat cari berkomunikasi orangtua pada anak. Mencoba memberikan jalan keluar bagi orangtua yang memiliki permasalahan ini. Manfaat dilakukannya penelitian ini ialah peneliti dapat memberikan pengetahuan serta pemahaman kepada mahasiswa dan masyarakat tentang bagaimana komunikasi orangtua dan anak dipengaruhih oleh program yang mereka tonton

\section{HASIL DAN PEMBAHASAN}

Kehidupan manusia pada masa sekarang ini hampir tidak pernah lepas dari media massa baik itu televisi, koran, radio, ataupun internet. Setiap manusia hampir dapat dipastikan akan berhubungan dengan media massa. Dapat kita lihat berapa jam orang akan menonton televisi dalam satu hari. Menonton televisi tidak dapat demikian saja diasumsikan sebagai sebuah aktivitas yang berdimensi tunggal, apalagi sebagai sesuatu yang terjadi dengan begitu saja. ${ }^{3}$ Walaupun saat ini tontonan televisi sudah berganti ke gadget. Namun apa yang di tonton di youtube, instagram maupun tik tok, juga bagian dari acara televisi.

Saat ini, hal negatif sangat mudah kita jumpai. Media-media dengan sangat mudahnya menampilkan gambar yang fulgar, syur dan merangsang otak

\footnotetext{
${ }^{3}$ Budiman, Kris. 2002. Di depan Kotak Ajaib: Menonton Televisi sebagai Praktik Konsumsi. Yogyakarta: Galang Press, h.17
} 
orang yang menontonnya. Bahkan tidak sedikit yang berani langsung mempraktekkan apa yang mereka lihat di televis maupun di media sosial. Negara indonesia bukanlah negara islam melainkan negara demokrasi. Hal inilah yang banyak golongan tertentu menanggap jika perlihatkan dada dan paha bukan hal yang porno. Sehingga KPI (Komisi Penyiaran Indonesia) sebagai badan sensor juga tidak bisa berbuat banyak. Bayangkan jika hal tersebut ditonton oleh generasi muda indonesia. Apa yang akan tertanam diotak mereka saat ini hingga masa mendatang?

Melihat hal di atas, maka tidaklah aneh jika hal-hal yang dilarang agama muncul ditengah masyarakat terutama dikalangan muda. Yang paling mudah kita temukan disinetron-sinetron yang sering kali menampilkan adegan-adegan yang tidak sepantasnya dipertontonkan. Lalu siapa yang akan kita salahkan? Siapa yang bertanggungjawab? Penontonkah atau produser acara atau pemilik stasiun tv atau pemerintah? Banyak pertanyaan yang akan muncul. Dunia pendidikan pun bisa disalahkan dikarenakan para pendidik tidak maksimal. Namun yang pasti menjadi penanggungjawab pertama adalah keluarga dilingkungan rumah terutama orang tua yang diamanati Allah SWT untuk menjaga anaknya dari perbuatan yang bisa membuat anak-anak rusak akhlaknya. Allah SWT berfirman:

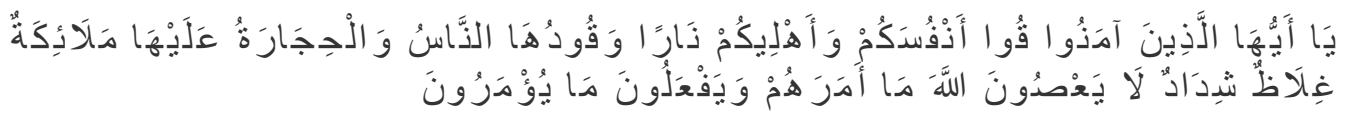

"Hai orang-orang yang beriman, peliharalah dirimu dan keluargamu dari api neraka yang bahan bakarnya adalah manusia dan batu; penjaganya malaikat-malaikat yang kasar, keras, dan tidak mendurhakai Allah terhadap apa yang diperintahkan-Nya kepada mereka dan selalu mengerjakan apa yang diperintahkan." QS.at-Tahriim: $6 .{ }^{4}$

Ayat di atas menjelaskan agar kita sebagai insan yang beriman kepada Allah harus menjaga diri kita sendiri sebelum memerintahkan orang lain. Setelah diri sendiri barulah kita menjaga keluarga kita agar terhindar dari siksa api neraka kelak. Sedikit lebih keras, Allah mengingatkan jika bahan bakar neraka kelak adalah manusia dan batu. Jika kita menganggap hal ini adalah biasa, maka kita harus muhasabahkan diri karena kurangnya rasa takut akan neraka berarti sama halnya dengan tidak takutnya kita sama neraka. Dan hal ini banyak terjadi di lingkungan kita. Anak-anak seolah tidak percaya akan adanya neraka.

Orang tua memegang peranan penting kearah mana sang anak want to be what. Entah anak kelak jadi tentara, polisi, dokter, dosen, pedagang maka orang tualah yang menentukan minat arah anak ingin jadi apa. Walaupun pada saat dewasa nanti mereka yang memutuskan sendiri. Namun sejak dini, orang tua secara tidak langsung menanamkan cita-cita anak tersebut. Dan hal ini banyak tidak disadari oleh orang tua. Dan jika orang tua tidak menyadarinya, maka orang tua akan bingung sendiri kenapa anaknya menginginkan cita-cita seperti ini. Misalnya anak yang tinggal dilingkungan pesantren akan beda dengan anak yang tinggal dilingkungan militer. Anak akan memilih sesuai dengan kebiasaan dia ketika kecil. Sekalipun anaknya tinggal di lingkungan militer tapi ingin pesantren, biasanya orangtuanya sering mengajak anak ke tempat pengajian, kajian islam, majelis taklim hingga merubah mindset anak.

\footnotetext{
${ }^{4}$ CV.as-Syifa, Al-Quran dan terjemahannya, Semarang, h.448.
} 
Manusia sebagai mahluk yang padagogik yang memerlukan edukasi dalam melaksanakan semua hal dalam kehidupan. Manusia memerlukan pendidikan dalam melaksanakan pendidikan karena manusia mempunyai potensi untuk mendidik dan juga potensi untuk dididik. ${ }^{5}$ Pendidikan bagi manusia sangat penting dan sudah menjadi kebutuhan primer. Jika manusia tidak mau mempelajari teori sebuah ilmu, maka yang terjadi adalah kualitas manusia tersebut turun drastis. Semakin mudah orang akan membodohi orang yang tidak berpendidikan. Bahkan orang yang tidak berpendidikan cenderung lebih mengambil solusi singkat jika menemukan masalah. Orang tua harus memiliki jiwa yang educated terhadap anak-anaknya. Jiwa inilah yang membuat orang tua menjadi the best parents.

Disini dapat dipahami bahwa pangkal permasalahan pembinaan mental dan akhlak anak adalah cepatnya perubahan nilai-nilai akhlak yang diakibatkan oleh pesatnya perkembangan ilmu pengetahuan dan teknologi yang mempunyai dua dampak, yaitu dampak positif dan dampak negatif. ${ }^{6}$ Perkembangan ilmu sangat pesat sehingga saat ini jarang orang yang bisa memfilter $100 \%$ berita maupun ilmu yang diserap. Bahkan lebih banyak negatifnya daripada positifnya. Hal inilah yang berdampak pada pola pikir orang tua. Orang tua yang banyak menonton film india misalnya, secara tidak langsung akan mendidik anak yang tidak jauh dengan pola pikir film india yang mereka tonton. Misalnya terlalu membawa perasaan ketika menghadapi masalah sehingga emosi yang lebih banyak ketimbang solusi. Beda halnya ketika mereka nonton film korea yang lebih cenderung kepada hal-hal yang berbau kemewahan.

Kita dapat mengetahui dampak positif perkembangan dunia melalui informasi-informasi yang ditampilkan oleh media massa, baik itu elektronik maupun cetak. Nilai-nilai negative akan tampak melenceng dari garis-garis budaya yang bisa mempengaruhi perilaku anak-anak dan pada akhirnya banyak anak-anak yang meniru apa yang ditayangkan dalam media tersebut.

Penelitian tentang paparan media elektronik sudah banyak dilakukan, baik di luar maupun di dalam negeri, terutama yang berasal dari media televisi. Seperti Noriko yang meneliti dampak paparan televisi terhadap anak-anak Tokyo ${ }^{7}$; Christakis dan Lumeng yang meneliti dampak tayangan televisi terhadap perilaku anak di Amerika Serikat dengan menggunakan subskala hiperaktif Indeks Masalah Perilaku ${ }^{8}$; atau Paavonen yang meneliti aktivitas menonton televisi anakanak di Finlandia yang berakibat pada gangguan tidur ${ }^{9}$; hingga Nazari, dkk yang meneliti siswa sekolah dasar di Iran yang melibatkan penggunaan perangkat televisi, video games, komputer, dan internet oleh anak. ${ }^{10}$ Hal ini banyak terlihat dikehidupan kita seperti menampilkan trend busana (busana yang tidak menutup aurat) yang tampak indah menurut mereka. Tentu hal ini akan diikuti oleh anak

\footnotetext{
${ }^{5}$ Zakiah Drajat,dkk. Ilmu Pendidikan Islam, (Jakarta: BUmi Aksara, 2001), h.16

${ }^{6}$ Hasan Langgulung, Pendidikan Islam Menghadapi Abad ke-21,(Jakarta: al-Huda, 2006), h. 185

${ }^{7}$ Noriko, Nishimura. (2003). Media Exposure and Development of Young Children, Infants and Television. NHK Broadcasting Studies 2006-2007 No.5

${ }^{8}$ Lumeng, Julie C., dkk. (2006). Television Exposure and Overweight Risk in Preschoolers. Arch Pediatr Adolesc Med.Vol. 160 : 417-422

${ }^{9}$ Paavonen, E. Juulia., dkk. (2006). TV Exposure Associated with Sleep Disturbances in 5- to 6-year-old Children. European Sleep Research Society. J. Sleep Res. (2006) 15, 154-161

10 Nazari, Mohammad Reza., dkk. (2012). Television Exposure as a Risk Factor for Aggressive Behavior Among Primary School Students. Vol 65, No. 8
} 
jika orang tua tidak memfilter apa yang ditonton anak. Tentu kita masih ingat dengan kejadian video porno yang dilakukan oleh dua artis ternama yang sampai hari ini orang-orangnya masih exist didunia entertaint. Sampai hari ini pun, video-video tersebut masih bisa dengan mudah diakses di internet dari gadget manapun.

Ketika media massa mengangkat suatu cerita fiksi dengan bahasa yang fulgar (membangkitkan syahwat), maka banyak sekali anak-anak mengaplikasikannya di kehidupan sehari-hari. Hingga menurut mereka bahasa tersebut dianggap biasa, padahal menurut akhlak dalam islam jelas salah besar. Misalnya dengan mengucapkan nama-nama hewan ke teman mainnya. Akhlak islam dapat dikatakan sebagai aklak yang islami adalah akhlak yang bersumber pada ajaran Allah dan Rasulullah. Akhlak islami ini merupakan amal perbuatan yang sifatnya terbuka sehingga dapat menjadi indikator seseorang apakah seorang muslim yang baik atau buruk. Akhlak ini merupakan buah dari akidah dan syariah yang benar. ${ }^{11}$

Bahkan tidak sedikit dari mereka berani mempraktekkan perbuatan keji itu keteman-temannya. Baik dalam keadaan saling suka maupun tidak saling suka. Akhirnya timbullah perzinahan dimana-mana. Tidak sedikit kita sering mendengar berita di televisi tentang perkosaan, pencabulan yang dilakukan oleh siswa terhadap siswi lainnya. Hal inilah yang ditakutkan oleh para orang tua terhadap anaknya. Hal ini sangat mudah kita dapatkan dilingkungan kita. Bisa melalui televisi lewat film-film, iklan, sinetron-sinetron, poster, spanduk dan lain sebagainya. Saat ini mudah kita akses, bahkan lewat gadget sekalipun dengan sekali klik.

Generasi bangsa indonesia akan mudah diatasi jika akhlak dan mentalnya baik. Jika sebaliknya, maka tunggulah kehancuran bangsa ini. Dinegara-negara afrika misalnya banyak dari mereka porak poranda diakibatkan karena krisis akhlak dan mentalnya. Terutama akhlak dan metal para generasi mudanya. Ketika anak sedang menonton televisi, ada baiknya orang tua mendampingi anak. Adegan-adegan yang menurut KPI (Komisi Penyiaran Indonesia) sudah disensor, namun pada hakikatnya belum disensor menurut pandangan agama islam secara khusus. Adegan berkelahi contohnya mudah diikuti oleh anak-anak. Bahkan ketika anak sedang bermain diluar pengawasan kita bisa saja anak melakukan pemukulan terhadap temannya. Ketika mereka membaca majalah atau koran, orang tua pun harus memperhatikan bacaan anak. Bacaan anak harus sesuai dengan standar usianya.

Masalah kenakalan remaja saat ini semakin meresahkan masyarakat, baik di negara-negara maju ataupun negara-negara yang sedang berkembang, termasuk Indonesia. Bahkan di Amerika saat ini para ahli mencari cara bagaimana mengatasi anak yang ketagihan gadget. Yang menjadi salah satu faktor terbesar penyebab dari kenakalan remaja di Indonesia adalah media elektronik. Dewasa ini media tersebut semakin meresahkan para orang tua terhadap remaja putra putrinya. Bagaimana tidak, televisi yang selama ini berperan sebagai media elektronik ternyata mampu menggelitik, mempengaruhi dan menggiring seluruh umat manusia. ${ }^{12}$

\footnotetext{
${ }^{11}$ Jurnal Pesona Dasar, Vol. 1 No. 4, Oktober 2015, hal 73 - 87., ISSN: 2337-9227

12 Awadl Manshur, Televisi Manfaat dan Mudarat, Jakarta: Fikahati Aneska,1996 Cet. 2, hal.7
} 
Orang tua harus cepat tanggap jika bacaan tersebut diluar batas umurnya. Beberapa tahun belakangan, dibuku-buku pelajaran juga sering ditemukan teks bacaan bahkan gambar yang mengandung konten pornograpi. Berdasarkan hal tersebut, maka diidentifikasi banyak dampak negative yang ditimbulkan media massa dan kurangnya perhatian orang tua terhadap perilaku anaknya, orang tua terlalu dalam memberikan kepada anak untuk mengakses media yang menampilkan hal yang tabuh dan banyaknya orang tua yang terlalu no care dalam menyikapi masalah.

\section{KESIMPULAN}

Orang tua harus cepat tanggap jika anak mengakses diluar batas umurnya. Beberapa tahun belakangan, dibuku-buku pelajaran juga sering ditemukan teks bacaan bahkan gambar yang mengandung konten pornograpi. Berdasarkan hal tersebut, maka diidentifikasi banyak dampak negative yang ditimbulkan media massa dan kurangnya perhatian orang tua terhadap perilaku anaknya, orang tua terlalu dalam memberikan kepada anak untuk mengakses media yang menampilkan hal yang tabuh dan banyaknya orang tua yang terlalu no care dalam menyikapi masalah. Sehingga kurangnya komunikasi yang akan tercipta antara anak kepada orangtua. Kurangnya komunikasi ini akan menghambat kemajuan dalam membina akhlak sang anak. Jalan keluar yang terbaik adalah mengurangi penggunaan media elektronik. Lebih banyak membangun komunikasi langsung dibanding komunikasi via media sosial. Sebisa mungkin membatasi anak menggunakan gadget nya untuk menonton program-program yang tidak sesuai dengan umurnya. Walaupun beberapa media sosial bisa disetting ke mode anak, namun hal itu msh bisa diakali oleh anak.

\section{DAFTAR PUSTAKA}

Al-Quran dan Terjemahannya, Semarang: CV.as-Syifa; 2002.

Awadl Manshur, Televisi Manfaat dan Mudarat, Cet. 2, Jakarta: Fikahati Aneska;1996.

Budiman, Kris. Di depan Kotak Ajaib: Menonton Televisi sebagai Praktik Konsumsi. Yogyakarta: Galang Press; 2002.

Hasan Langgulung, Pendidikan Islam Menghadapi Abad ke-21, Jakarta: al-Huda; 2006.

JURNAL PESONA DASAR, Vol. 1 No. 4, Oktober 2015, hal 73 - 87., ISSN: 2337-9227

Lumeng, Julie C., dkk. Television Exposure and Overweight Risk in Preschoolers. Arch Pediatr Adolesc Med.Vol. 160 : 417-422. 2006.

Muazim Syair, Porsi Pendidikan Agama Perlu Ditambah, Sriwijaya Post, Jumat 12 Mei 2005. website sriwijaya pos

Nazari, Mohammad Reza., dkk. Television Exposure as a Risk Factor for Aggressive Behavior Among Primary School Students. Vol 65, No. 8. 2012.

Noriko, Nishimura. Media Exposure and Development of Young Children, Infants and Television. NHK Broadcasting Studies 2006-2007 No.5 
Paavonen, E. Juulia., dkk. TV Exposure Associated with Sleep Disturbances in 5to 6-year-old Children. European Sleep Research Society. J. Sleep Res. (2006) 15, 154-161. 2006.

Zakiah Drajat,dkk. Ilmu Pendidikan Islam, Jakarta: Bumi Aksara; 2001 